\title{
Effect of Saccharomyces cerevisiae on Rumen Fermentation Characteristics, Nutrient Degradation and Cellulase Activity of Steers Fed Diets with Different Concentrate to Forage Ratios
}

\author{
Gengzhi Ding, Ying Chang, Zhenming Zhou, Liping Ren, Qingxiang Meng*
}

State Key Laboratory of Animal Nutrition, College of Animal Science and Technology, China Agricultural University, Beijing, China *Corresponding author: qxmeng@cau.edu.cn

Received October 04, 2014; Revised November 12, 2014; Accepted December 24, 2014

\begin{abstract}
The objective of current study was to evaluate effect of Saccharomyces cerevisiae (SC) on rumen fermentation characteristics and fiber degradation in steers fed diets with different concentrate levels. Ten Simental $\times$ Local breed steers fitted with rumen fistulas were assigned to control and treatment groups. Steers were fed the same basal diets but the treatment groups received SC supplementation $\left(8 \times 10^{9} \mathrm{cfu} / \mathrm{h} / \mathrm{d}\right)$ following a 2-period crossover design. Each period was comprised of four phases. From the $1^{\text {st }}$ to the $4^{\text {th }}$ phase, steers were fed in a stepwise fashion with incremental levels of concentrate diets at concentrate to forage ratios (CTFR) of 30:70, 50:50, 70:30 and 90:10, respectively. MIXED procedure was used to analysis effect of SC supplementation on parameters. Linear and quadratic responses for dietary CTFR were assessed using orthogonal polynomial contrast statements. The results showed that with dietary CTFR increasing, rumen $\mathrm{pH}$, acetate and isobutyrate molar proportion, acetate: propionate, degradation rate $\left(c_{\mathrm{DM}}, c_{\mathrm{NDF}}\right)$ and effective degradability $\left(\mathrm{ED}_{\mathrm{DM}}, \mathrm{ED}_{\mathrm{NDF}}\right)$ of $\mathrm{CRH}$ linearly decreased (L; $P$ $<0.01$ ); TVFA concentration, molar proportion of propionate, butyrate, valerate and isovalerate and enzyme fibrotic activities linearly increased $(\mathrm{L} ; P<0.01)$, but concentration of rumen ammonia $\mathrm{N}$, D+L-lactate and rapidly degradable fraction $\left(a_{\mathrm{DM}}, a_{\mathrm{NDF}}\right)$ of $\mathrm{CRH}$ presented quadratic variation $(\mathrm{Q} ; P<0.01)$. Regardless of dietary CTFR, rumen $\mathrm{pH}, c_{\mathrm{DM}}, c_{\mathrm{NDF}}, \mathrm{ED}_{\mathrm{DM}}, \mathrm{ED}_{\mathrm{NDF}}$ of $\mathrm{CRH}$ and enzyme fibrotic activities with SC supplementation was higher compared to control groups $(P<0.05)$. Overall, SC possesses the capacity to stabilize rumen $\mathrm{pH}$ and to enhance fiber degradation.
\end{abstract}

Keywords: fibrolytic activity, in situ, rumen fermentation characteristics, Saccharomyces cerevisiae, steer

Cite This Article: Gengzhi Ding, Ying Chang, Zhenming Zhou, Liping Ren, and Qingxiang Meng, "Effect of Saccharomyces cerevisiae on Rumen Fermentation Characteristics, Nutrient Degradation and Cellulase Activity of Steers Fed Diets with Different Concentrate to Forage Ratios.” World Journal of Agricultural Research, vol. 2, no. 6 (2014): 303-308. doi: 10.12691/wjar-2-6-10.

\section{Introduction}

Yeast additive obtained from Saccharomyces cerevisiae (SC) has been used for many years as a substitute for antibiotics to enhance rumen fermentation and improve production efficiency in ruminant production systems, especially after antibiotics were banned by the European Union [1]. Many studies have shown that SC strain CNCM I-1077 (Lallemand, France) has a positive effect on milk production and daily feed intake of dairy cows and goats $[2,3,4]$.

One of the primary mechanisms by which live yeasts affect animal performance seems to be related to the improvement in rumen function [5]. Published results have shown that SC can function in stabilization of rumen $\mathrm{pH}[6]$, and in reduction of total volatile fatty acid (TVFA), ammonia $\mathrm{N}$ and lactic acid concentrations [5]. However, the effect of live yeast on rumen fermentation characteristics is inconsistent $[3,7,8,9]$. Similarly, the effect of live yeast on nutrient degradation in the rumen is also variable. Guedes et al. reported that supplementing with live yeast increased rumen neutral detergent fiber (NDF) degradation of maize silage [10], whereas Mir and Mir (1994) reported that live yeast supplementation had no effect on rumen dry matter (DM) or NDF degradation [9]. Part of these differences may be attributed to the different basal diets, especially at different dietary concentrate levels [11].

Major studies related live yeast have focused on dairy cattle and small ruminants such as sheep and goats [2,3,4]. Little attention has been paid to the effect of live yeast on beef cattle. Therefore, the objectives of the present study were to investigate the effect of supplementation with live yeast on rumen fermentation characteristics, nutrient degradation and cellulase activity of beef cattle fed diets with different concentrate to forage ratios. 


\section{Material and Methods}

\subsection{Animals, Diets and Experimental Design}

Ten Simental $\times$ Local crossbred steers $(450 \pm 50 \mathrm{~kg}$ body weight) fitted with $10-\mathrm{cm}$ diameter rumen fistulas were used as experimental animals. Approval from the Animal Care and Use Committee of the College of Animal Science and Technology of China Agricultural University (ACUC-CAST, \#20120806BCRC004) was obtained before commencement of this study. Each of the steers was housed in a tie-stall barn and feed, fresh water were available ad libitum. Steers were randomly assigned to one of two treatments: the control group received the basal diet with no SC supplementation and the treatment group received the basal diet with SC supplementation following a 2-period crossover design. Each period was comprised of four phases, each of which lasted for 17 days including 10 days for dietary adaptation, 6 days for the degradation study described below and 1 day for rumen liquor sampling. From the $1^{\text {st }}$ to the $4^{\text {th }}$ phase, steers were fed in a stepwise fashion with constant increases in the concentrate level. The stepwise diets (Table 1) were formulated to meet the nutrient requirements [12], with the concentrate to forage ratios (CTFR) at 30:70 (Phase 1), 50:50 (Phase 2), 70:30 (Phase 3), and 90:10 (Phase 4), respectively. The diets were well mixed and pressed into high density bales using a specialized wrapping machine before each phase. During the experiment, active dry yeast of SC (CNCM I1077, Lallemand, France) was offered and dosed daily at $8 \times 10^{9} \mathrm{cfu} / \mathrm{hd} / \mathrm{d}$ directly into the rumen through fistulas just before morning feeding.

Table 1. Ingredients and nutrient composition of basal diets

\begin{tabular}{ccccc}
\hline \multirow{2}{*}{ Item } & \multicolumn{3}{c}{ Dietary concentrate to forage ratios } \\
\cline { 2 - 5 } & $30: 70$ & $50: 50$ & $70: 30$ & $90: 10$ \\
\hline Ingredient , \% DM & & & & \\
Steam-flaked maize $^{1}$ & 13.00 & 34.00 & 54.00 & 74.00 \\
Soybean curb residue $^{2}$ & 15.20 & 13.90 & 13.70 & 13.30 \\
Maize stalks & 57.00 & 38.00 & 19.00 & 1.00 \\
Chinese ryegrass & 4.00 & 5.00 & 6.00 & 6.00 \\
Alfalfa pellets & 9.00 & 7.00 & 5.00 & 3.00 \\
Salt & 0.50 & 0.50 & 0.50 & 0.50 \\
Limestone & 0.40 & 0.70 & 1.10 & 1.50 \\
Dicalcium phosphate & 0.20 & 0.20 & 0.00 & 0.00 \\
Magnesium oxide & 0.20 & 0.20 & 0.20 & 0.20 \\
Sodium bicarbonate & 0.50 & 0.50 & 0.50 & 0.50 \\
Nutrient , \% DM & & & & \\
ME , MJ/kg & 9.10 & 10.30 & 11.70 & 12.80 \\
CP & 12.70 & 12.70 & 12.70 & 12.80 \\
NDF & 54.20 & 42.70 & 31.60 & 20.80 \\
Starch & 12.20 & 26.80 & 40.90 & 54.20 \\
Ca & 0.64 & 0.64 & 0.63 & 0.67 \\
P & 0.32 & 0.34 & 0.33 & 0.35 \\
\hline 1 flaking density is 360 g/L & & & &
\end{tabular}

flaking density is $360 \mathrm{~g} / \mathrm{L}$

2 a by-product comes from soybean processed into bean curd which is a kind of food in China.

\subsection{In Situ Rumen Incubation}

Chinese ryegrass hay (CRH) was ground through a 2mm screen in a Wiley laboratory mill and then $5 \mathrm{~g}$ DM from the samples were placed into separate number-coded nylon bags $(8 \times 12 \mathrm{~cm})$. The pore size of the nylon bags was $38 \mu \mathrm{m}$. For incubations, each steer had a total of three bags as replicates/ sample. Rumen incubations were performed according to the method of Ørskov et al. [13] but following the gradual addition/all out schedule [14]. Samples were incubated in the rumen for 168, 96, 48, 24, 12, 6, and $0 \mathrm{~h}$, respectively; for NDF, $240 \mathrm{~h}$ was added [15]. All bags were inserted at the same time (08:00) just before morning feed apart from the $12 \mathrm{~h}$ bags and $6 \mathrm{~h}$ bags, which were inserted at 07:00 and 13:00. After incubation, bags removed from the rumen were rinsed under a cold stream of tap water to remove excess rumen contents and to stop microbial activity. The bags were then washed with cool water without detergent in a washing machine and subsequently dried at $60^{\circ} \mathrm{C}$ for $48 \mathrm{~h}$. The $0 \mathrm{~h}$ incubation samples were only washed under the same conditions. The bags were weighed and residues were pooled according to treatments and incubation times and then ground through a 1-mm screen. DM and NDF were analyzed. Data for DM and NDF disappearance at different incubation times were fitted to the following models [13]:

$$
\begin{aligned}
& p=a+b\left(1-\mathrm{e}^{-\mathrm{ct}}\right) \\
& \mathrm{ED}=a+b \times c /(c+k)
\end{aligned}
$$

where $p=$ fraction disappearance at time $t, a=$ soluble or rapidly degradable fraction, $b=$ insoluble but potentially degradable fraction, $c$ = rate constant of degradation of potentially degradable insoluble fraction $(/ \mathrm{h}), t=$ time of rumen incubation $(\mathrm{h}), k=$ rumen passage rate $(/ \mathrm{h})$, and ED $=$ effective degradability.

\subsection{Rumen Fluid Collection}

Rumen samples were collected by hand from four locations in the rumen and reticulum through rumen fistulas at $3 \mathrm{~h}$ after morning feeding on the last day of each phase. Aliquots were filtered through two layers of cheese cloth, and immediately analyzed for $\mathrm{pH}$ with an electric pH meter (Model PHS-3C, Shanghai Leici Scientific Instrument Co., Ltd., China); $40 \mathrm{ml}$ of filtered rumen fluid and about $50 \mathrm{~g}$ of the filter residue were placed into $50 \mathrm{ml}$ centrifuge tubes, then all of the tubes were placed in liquid nitrogen immediately for ammonia-N, volatile fatty acid (VFA), D+L-lactate acid concentration and cellulase activity determination, respectively.

\subsection{Measurements}

Dry matter in feedstuff and their residues was measured by drying at $60^{\circ} \mathrm{C}$ for $48 \mathrm{~h}$ in a forced-air oven. NDF was measured using an ANKOM $^{200}$ Fiber Analyzer (ANKOM Technology Corp., Fairport, NY, USA) [16]. NDF was assayed with heat stable amylase and without sodium sulfite and expressed inclusive of residual ash [17]. Samples of rumen fluid were centrifuged at $10000 \times \mathrm{g}$ and supernatants were collected for ammonia N, VFA and $\mathrm{D}+\mathrm{L}-$ lactate analysis. Concentration of ammonia $\mathrm{N}$ was determined using the colorimetric method according to Chaney and Marbach (1962) [18]. Concentration of VFA was determined by gas-liquid chromatography (Shimadzu GC-141 B, Kyoto, Japan) using 2-ethylbutyrate as internal standard. Concentration of $\mathrm{D}+\mathrm{L}$-lactate was determined using ion chromatography according to $\mathrm{Mu}$ et al. [19]. Another portion of rumen fluid was centrifuged at $2000 \times \mathrm{g}$ and the supernatants were used for xylanase, avicelase, $\beta$ glucanase, and carboxymethyl cellulose activity 
determination which was detected by the dinitrosalicylic acid (DNS) method at $540 \mathrm{~nm}$ wavelength using ELIASA according to Yue et al. [20] and Dashtban et al. [21]. The unit (U) of cellulase activity was defined as the amount of enzyme in $1 \mathrm{ml}$ supernatant that liberates $1 \mu \mathrm{mol}$ of xylose or glucose per minute when temperature $=39^{\circ} \mathrm{C}$ and $\mathrm{pH}=$ 6.8 .

\subsection{Statistical Analyses}

SAS (1990) software was used for statistical analysis. Rumen fermentation data, degradation characteristics, and rumen fibrolytic activity data were analyzed using the MIXED procedure with the model:

$$
\begin{aligned}
& Y_{i j k l}=\mu+\text { Period }_{i}+\text { Treatment }_{j} \\
& \left.+ \text { Diet }_{k}+\text { (Treatment }_{j} \times \text { Diet }_{k}\right)+ \text { Steer }_{l}+\varepsilon_{\mathrm{ijkl}}
\end{aligned}
$$

where $\mu$ represented the overall mean, Period represented the period (1 or 2), Treatment accounted for the fixed effect of yeast supplementation, Diet represented the fixed effect of different dietary CTFR, Steer accounted for the random effect of each individual animal, $\varepsilon$ account for the unexplained random error. Linear and quadratic responses for dietary CTFR were assessed using orthogonal polynomial contrast statements.

\section{Results}

The results revealed that there were no significant differences between the 2 periods and there were no interactions between dietary CTFR and SC $(P>0.1$; Table 2- Table 5) for most parameters. Therefore, the main effects of dietary CTFR and SC supplementation are discussed independently.

\subsection{Effect of SC on Rumen Fermentation Characteristics of Steers Fed Different Dietary CTFRs}

Rumen fermentation characteristics were significantly affected by dietary CTFR $(P<0.01)$. With dietary CTFR increasing, rumen $\mathrm{pH}$ values, acetate and isobutyrate molar proportion and acetate: propionate (A:P) linearly (L, $P<0.01)$ decreased; TVFA concentration and molar proportion of propionate, butyrate, valerate and isovalerate linearly $(\mathrm{L}, P<0.01)$ increased; ammonia $\mathrm{N}$ and $\mathrm{D}+\mathrm{L}-$ lactate concentration presented quadratic $(\mathrm{Q}, P<0.01)$ variation trend (Table 2).

Regardless of dietary CTFR, there was a difference ( $P$ $<0.01$ ) in rumen $\mathrm{pH}$ between SC supplementation and control groups (Table 2), but no differences $(P>0.05)$ were observed in concentration of ammonia N, TVFA and $\mathrm{D}+\mathrm{L}-$ lactate and molar proportions of individual VFA.

Table 2. Effect of SC supplementation on rumen $\mathrm{pH}$, volatile fatty acid (VFA; mmol/L), ammonia $\mathrm{N}(\mathrm{mg} / 100 \mathrm{~mL})$ and $\mathrm{D}+\mathrm{L}-\mathrm{lactate}(\mathrm{mmol} / \mathrm{L})$

\begin{tabular}{|c|c|c|c|c|c|c|c|c|c|c|c|c|c|}
\hline \multirow{2}{*}{ Item } & \multicolumn{4}{|c|}{ CTFR } & \multirow{2}{*}{ SEM } & \multicolumn{2}{|c|}{ SC } & \multirow{2}{*}{ SEM } & \multicolumn{3}{|c|}{$\mathrm{P}$ value } & \multicolumn{2}{|c|}{ Probability } \\
\hline & $30: 70$ & $50: 50$ & 70:30 & $90: 10$ & & $\mathrm{~N}$ & $\mathrm{Y}$ & & CTFR & SC & $\mathrm{CTFR} \times \mathrm{SC}$ & $\mathrm{L}$ & $\mathrm{Q}$ \\
\hline $\mathrm{pH}$ & 6.63 & 6.42 & 6.23 & 6.08 & 0.0 & 6.29 & 6.38 & 0.02 & $<0.01$ & $<0.01$ & 0.32 & $<0.01$ & 0.26 \\
\hline Ammonia N & 5.9 & 5.1 & 8.7 & 3.6 & 0.5 & 6.2 & 5.4 & 0.4 & $<0.01$ & 0.12 & 0.94 & 0.89 & $<0.01$ \\
\hline TVFA & 80.9 & 92.1 & 103.7 & 107.3 & 2.6 & 97.6 & 94.4 & 1.9 & $<0.01$ & 0.25 & 1.00 & $<0.01$ & 0.33 \\
\hline D+L-lactate & 9.7 & 10.0 & 8.5 & 9.9 & 0.2 & 9.6 & 9.5 & 0.1 & $<0.01$ & 0.53 & 1.00 & 0.53 & 0.01 \\
\hline \multicolumn{14}{|c|}{ Molar proportion } \\
\hline Acetate & 68.9 & 67.5 & 60.7 & 56.6 & 0.3 & 63.3 & 63.6 & 0.2 & $<0.01$ & 0.34 & 0.02 & $<0.01$ & $<0.01$ \\
\hline Propionate & 20.7 & 20.4 & 27.3 & 27.8 & 0.3 & 24.0 & 24.1 & 0.2 & $<0.01$ & 0.84 & 0.03 & $<0.01$ & 0.23 \\
\hline Butyrate & 8.4 & 9.8 & 9.3 & 12.1 & 0.3 & 10.0 & 9.8 & 0.2 & $<0.01$ & 0.50 & 0.23 & $<0.01$ & $<0.01$ \\
\hline Valerate & 0.7 & 0.9 & 1.2 & 1.6 & 0.0 & 1.1 & 1.1 & 0.0 & $<0.01$ & 0.49 & 0.43 & $<0.01$ & $<0.01$ \\
\hline Isobutyrate & 0.4 & 0.4 & 0.3 & 0.2 & 0.0 & 0.3 & 0.3 & 0.0 & $<0.01$ & 0.43 & 0.19 & $<0.01$ & 0.24 \\
\hline Isovalerate & 0.8 & 1.0 & 1.3 & 1.3 & 0.1 & 1.1 & 1.1 & 0.1 & $<0.01$ & 0.83 & 0.81 & $<0.01$ & 0.24 \\
\hline$A: P$ & 3.3 & 3.3 & 2.2 & 2.0 & 0.0 & 2.7 & 2.7 & 0.0 & $<0.01$ & 0.53 & 0.10 & $<0.01$ & 0.06 \\
\hline
\end{tabular}
concentrations and molar proportion of VFAs (\%) of steers fed diets with different concentrate to forage ratios

$\mathrm{N}$ - control groups, Y- with SC supplementation; L-linear responses of dietary CTFR; Q-quadratic responses of dietary CTFR.

\subsection{Effect of SC on CRH Degradation Characteristics Of Steers Fed Different Dietary CTFRs}

DM degradation characteristics of $\mathrm{CRH}$ are shown in Table 3. With dietary CTFR increasing, rapidly degradable fraction of DM $\left(a_{\mathrm{DM}}\right)$ presented quadratic $(\mathrm{Q}$, $P<0.01)$ variation trend; potentially degradable fraction of DM $\left(b_{\mathrm{DM}}\right)$ present no significant variation trend $(\mathrm{L}, P=$ $0.10 ; \mathrm{Q}, P=0.69)$; degradation rate $\left(c_{\mathrm{DM}}\right)$ and effective degradability of DM (ED $\left.\mathrm{EM}_{\mathrm{DM}}\right)$ linearly $(\mathrm{L}, P<0.01)$ decreased.

NDF degradation characteristics of CRH are shown in Table 4. With dietary CTFR increasing, rapidly degradable fraction of NDF $\left(a_{\mathrm{NDF}}\right)$ presented quadratic $(\mathrm{Q}$, $P=0.01)$ variation trend; potentially degradable fraction of NDF $\left(b_{\mathrm{NDF}}\right)$ present no significant variation trend (L, $P$
$=0.11 ; \mathrm{Q}, P=0.26)$; degradation rate $\left(c_{\mathrm{NDF}}\right)$ and effective degradability of $\mathrm{DM}\left(\mathrm{ED}_{\mathrm{NDF}}\right)$ linearly $(\mathrm{L}, P<0.01)$ decreased.

Whatever CTFR, no differences $(P>0.05)$ were observed for $a_{\mathrm{DM}}, b_{\mathrm{DM}}$ and $a_{\mathrm{NDF}}$ of $\mathrm{CRH}$ between SC supplementation and control treatment; $c_{\mathrm{DM}}, \mathrm{ED}_{\mathrm{DM}}, c_{\mathrm{NDF}}$ and $\mathrm{ED}_{\mathrm{NDF}}$ of $\mathrm{CRH}$ with SC supplementation was higher $(P<0.01)$ compared to the control groups, but $b_{\mathrm{NDF}}$ with SC supplementation was lower $(P<0.05)$ than control groups (Table 3 and Table 4).

In addition, relative effective DM and NDF degradability of CRH presented an increasing trend with dietary CTFR increasing and it reached $4.44 \%$ (calculated from $(43.22 \%-40.98 \%) / 43.22 \% \times 100 \%)$ and $6.83 \%$ (calculated from $(29.44 \%-27.30 \%) / 27.30 \% \times 100 \%)$ respectively when dietary CTFR reached 90:10. 
Table 3. Effect of SC supplementation on DM rumen degradation characteristics of Chinese ryegrass hay of steers fed diets with different concentrate to forage ratios

\begin{tabular}{|c|c|c|c|c|c|c|c|c|c|c|c|c|c|}
\hline \multirow{2}{*}{ Item } & \multicolumn{4}{|c|}{ CTFR } & \multirow{2}{*}{ SEM } & \multicolumn{2}{|c|}{ SC } & \multirow{2}{*}{ SEM } & \multicolumn{3}{|c|}{$\mathrm{P}$ value } & \multicolumn{2}{|c|}{ Probability } \\
\hline & $30: 70$ & $50: 50$ & $70: 30$ & $90: 10$ & & $\mathrm{~N}$ & $\mathrm{Y}$ & & CTFR & SC & $\mathrm{CTFR} \times \mathrm{SC}$ & $\mathrm{L}$ & Q \\
\hline$a, \%$ & 14.5 & 20.5 & 15.3 & 16.7 & 0.5 & 16.7 & 16.8 & 0.3 & $<0.01$ & 0.79 & 0.95 & 0.73 & $<0.01$ \\
\hline$b, \%$ & 56.8 & 54.7 & 58.0 & 58.6 & 0.9 & 56.8 & 57.2 & 0.6 & 0.01 & 0.68 & 1.00 & 0.10 & 0.69 \\
\hline$c, \% / \mathrm{h}$ & 2.4 & 1.6 & 1.9 & 1.3 & 0.1 & 1.7 & 2.0 & 0.0 & $<0.01$ & $<0.01$ & 0.06 & $<0.01$ & 0.20 \\
\hline $\mathrm{ED}, \%$ & 46.7 & 47.2 & 45.6 & 42.3 & 0.3 & 44.8 & 46.1 & 0.2 & $<0.01$ & $<0.01$ & 0.51 & $<0.01$ & $<0.01$ \\
\hline
\end{tabular}

$\mathrm{N}$ - control groups, Y- with SC supplementation, $a$-soluble or rapidly degradable fraction, $b$ - insoluble but potentially degradable fraction, $c$ - degradation rate of potentially degradable fraction, ED- effective degradability; L-linear responses of dietary CTFR; Q-quadratic responses of dietary CTFR.

Table 4. Effect of SC supplementation on NDF rumen degradation characteristics of Chinese ryegrass hay of steers fed diets with different concentrate to forage ratios

\begin{tabular}{|c|c|c|c|c|c|c|c|c|c|c|c|c|c|}
\hline \multirow{2}{*}{ Item } & \multicolumn{4}{|c|}{ CTFR } & \multirow{2}{*}{ SEM } & \multicolumn{2}{|c|}{ SC } & \multirow{2}{*}{ SEM } & \multicolumn{3}{|c|}{$\mathrm{P}$ value } & \multicolumn{2}{|c|}{ Probability } \\
\hline & $30: 70$ & $50: 50$ & $70: 30$ & $90: 10$ & & $\mathrm{~N}$ & $\mathrm{Y}$ & & CTFR & SC & $\mathrm{CTFR} \times \mathrm{SC}$ & $\mathrm{L}$ & $Q$ \\
\hline$a, \%$ & -0.9 & 2.7 & -1.6 & -1.1 & 0.6 & -0.6 & 0.1 & 0.4 & $<0.01$ & 0.25 & 0.89 & 0.05 & 0.01 \\
\hline$b, \%$ & 65.7 & 66.9 & 69.6 & 68.9 & 0.8 & 68.7 & 66.9 & 0.5 & $<0.01$ & 0.02 & 0.31 & 0.26 & 0.11 \\
\hline$c, \% / h$ & 2.4 & 1.4 & 1.8 & 1.2 & 0.1 & 1.6 & 1.8 & 0.0 & $<0.01$ & $<0.01$ & 0.49 & $<0.01$ & 0.07 \\
\hline $\mathrm{ED}, \%$ & 35.9 & 35.4 & 33.5 & 28.5 & 0.3 & 32.6 & 34.1 & 0.2 & $<0.01$ & $<0.01$ & 0.54 & $<0.01$ & $<0.01$ \\
\hline
\end{tabular}

$\mathrm{N}$ - control groups, Y- with SC supplementation, $a$-soluble or rapidly degradable fraction, $b$ - insoluble but potentially degradable fraction, $c$ - degradation rate of potentially degradable fraction, $k$ - passage rate, ED- effective degradability; L-linear responses of dietary CTFR; Q-quadratic responses of dietary CTFR.

\subsection{Effect of SC on Cellulase Activity of Steers Fed Different Dietary CTFRs}

Dietary CTFR significantly affected $(P<0.01)$ xylanase, CMCase, avicelase, and $\beta$-glucanase activity and which linearly (L, $P<0.01$ ) increased with dietary CTFR increasing (Table 5).
Regardless of dietary CTFR, compared with control groups, no difference $(P=0.10)$ was observed for CMCase in SC supplementation groups; while xylanase and avicelase activity were higher $(P<0.05)$ and $\beta$ glucanase activity showed an increasing tendency $(P=$ 0.05 ) with SC supplementation (Table 5).

Table 5. Effect of SC supplementation on rumen cellulase activity (mU) of steers fed diets with different concentrate to forage ratios

\begin{tabular}{|c|c|c|c|c|c|c|c|c|c|c|c|c|c|}
\hline \multirow{2}{*}{ Item } & \multicolumn{4}{|c|}{ CTFR } & \multirow{2}{*}{ SEM } & \multicolumn{2}{|c|}{ SC } & \multirow{2}{*}{ SEM } & \multicolumn{3}{|c|}{$\mathrm{P}$ value } & \multicolumn{2}{|c|}{ Probability } \\
\hline & $30: 70$ & $50: 50$ & $70: 30$ & $90: 10$ & & $\mathrm{~N}$ & $\mathrm{Y}$ & & CTFR & SC & $\mathrm{CTFR} \times \mathrm{SC}$ & $\mathrm{L}$ & $\mathrm{Q}$ \\
\hline Xylanase & 200.8 & 241.3 & 235.1 & 249.8 & 4.9 & 224.1 & 239.5 & 3.5 & $<0.01$ & $<0.01$ & 0.10 & $<0.01$ & 0.24 \\
\hline CMC-ase & 30.2 & 38.7 & 37.2 & 38.0 & 1.6 & 34.6 & 37.4 & 1.2 & $<0.01$ & 0.10 & 0.91 & $<0.01$ & 0.07 \\
\hline Avicelase & 104.8 & 140.0 & 141.1 & 190.5 & 8.2 & 134.4 & 153.7 & 5.8 & $<0.01$ & 0.02 & 0.30 & $<0.01$ & 0.58 \\
\hline$\beta$-glucanase & 74.2 & 94.1 & 98.6 & 116.5 & 6.2 & 89.7 & 102.0 & 4.4 & $<0.01$ & 0.05 & 0.74 & $<0.01$ & 0.99 \\
\hline
\end{tabular}

$\mathrm{N}$ - control groups, Y- with SC supplementation, L-linear responses of dietary CTFR; Q-quadratic responses of dietary CTFR.

\section{Discussion}

\subsection{Effect of Dietary CTFR on Rumen Fermentation Characteristics}

Variation trend of rumen $\mathrm{pH}$ and concentration of VFA and $\mathrm{D}^{+} \mathrm{L}-$ lactate with dietary CTFR increasing was consistent with other studies [22] and which was easy to understand. When dietary CTFR was higher, more readily fermentable carbohydrates (mainly starch) were ingested into the rumen, which brought about more organic acid production such as VFA and $\mathrm{D}+\mathrm{L}$-lactate contributing to lower rumen $\mathrm{pH}$ [5].

Ammonia in the rumen is a pool with several inputs and exits. Ammonia is derived from degradation of dietary protein and dietary non-protein nitrogen (NPN), from hydrolysis of urea recycled to the rumen and from degradation of microprotein (MCP). Ammonia disappears from the rumen pool due to uptake by microbes, absorption through the rumen wall and flushing to the omasum. Changes in any of these six factors will alter the concentration of ammonia in the rumen [23,24]. With dietary CTFR increasing, rumen bacteria increases and more ammonia $\mathrm{N}$ is needed to synthesize MCP, which results in lower ammonia $\mathrm{N}$. However, the increased level of concentrate leads to more acid matter which can conversely liberate ammonia as ammonium ion $\left(\mathrm{NH}_{4}{ }^{+}\right)$. The ammonium ion inhibits ammonia absorption as well as facilitating ammonia $\mathrm{N}$ in blood recycling to the rumen, which results in a higher ammonia $\mathrm{N}$ concentration in the rumen [23]. Therefore, rumen ammonia $\mathrm{N}$ concentration fluctuated with variation of concentrate level.

\subsection{Effect of SC Supplementation on Rumen Fermentation Characteristics}

Chaucheyras-Durand et al. reported that live yeast can scavenge unnecessary oxygen in the rumen and provide some bioactive substance [5]. Due to the metabolic activity of live yeast, ciliate entodiniomorphid protozoa are stimulated with more starch granules engulfing and lactate-metabolizing bacteria such as $S$. bovis are restrained. Consequently, concentration of VFA and D+Llactate decreased and rumen $\mathrm{pH}$ increased $[25,26,27,28]$.

In the present study, effect of SC supplementation on rumen $\mathrm{pH}$, concentration of TVFA and $\mathrm{D}+\mathrm{L}$-lactate was consistent with some previous studies $[6,10,29,30]$ but inconsistent with others [3,31] which reported that SC had a negative effect on rumen $\mathrm{pH}$ or improved TVFA concentration.

Some previous experiments showed that SC supplementation altered acetate: propionate [10,28,31] or 
proportions of branched-chain VFA (isobutyrate and isovalerate) [32,33], which means that rumen fermentation patterns was altered. However, no differences $(P>0.05)$ of individual VFA including branched-chain VFA molar proportions between SC and control groups were observed in current experiment.

Previous studies indicated that yeast additives either stimulate rumen ammonia $\mathrm{N}$ uptake by bacteria, which allows better growth of these species in the rumen, or they stimulate the growth of cellulolytic bacteria, which could use more rumen ammonia $\mathrm{N}$ to synthesize cellular nitrogenous components [34], hence the concentration of rumen ammonia would be decreased by live yeast [8]. However, no significant reduction for rumen ammonia $\mathrm{N}$ was observed between SC supplementation and control groups in the present experiment, and the result was consistent with previous studies [10,33].

\subsection{Effect of Dietary CTFR on Fiber Degradation}

From above discussion of effect of dietary CTFR on rumen $\mathrm{pH}$, effect of which on fiber degradation characteristics is easy to understand. Fiber is degraded by fiber-degrading bacteria, but the major fiber-degrading bacteria such as Fibrobacter succinogenes, Ruminococcus albus and $R$. flavfaciens are sensitive to low pH [35]. With dietary CTFR increasing, rumen $\mathrm{pH}$ linearly decreased, fiber-degrading bacteria activity was restricted [5], consequently fiber degradation rate and effective degradability linearly decreased.

However, in present experiment, cellulase activity linearly increased with dietary CTFR increasing which is contrary to our knowledge and the experimental results (fiber degradation rate linearly decreased). The main reason may be related to the $\mathrm{pH}$ value when cellulase activity was detected.

\subsection{Effect of SC Supplementation on Fiber Degradation}

Besides the positive effect of SC on rumen $\mathrm{pH}$, SC still possesses the capacity to scavenge oxygen traces in the rumen which leads to lower redox potential [36,37]. Hence, suitable acidity and favorable ecological conditions were created for the growth and activities of anaerobic microorganisms, consequently the number or activity of fiber-degrading bacteria were enhanced, which is beneficial to improve DM and NDF degradation [38]. In the present study, cellulase activity was proved to be increased with SC supplementation (Table 5), and whether the number of fiber-degrading bacteria could be enhanced will be evaluated in a future study.

However, an improvement with SC supplementation in rumen fiber degradation was not always observed. Some previous studies reported that SC supplementation improved rumen fiber degradation [10,34], which is consistent with the present study, whereas others reported there was no effect with SC supplementation on fiber degradation $[39,40]$. Similarly, improvement of SC on cellulase activity was not always observed [41]. The inconsistent results may be related to physiological status, breed of animals, feed composition or concentrate to forage ratio, yeast strain and dosage and more research needs to be done in the future to evaluate effect of SC on fiber degradation under different conditions.

\section{Conclusions}

Dietary CTFR had a significant effect on rumen fermentation characteristics, fiber degradation and rumen cellulase activity. SC possesses the capacity to stabilize rumen $\mathrm{pH}$ and to enhance fiber degradation and cellulase activity.

\section{Acknowledgements}

This study was financially supported by the Earmarked Fund for Modern Agro-Industry Technology Research System (Beef Cattle and Yaks, CARS-38), and the Chinese Universities Scientific Fund (No. 2013QJ071)”. The authors acknowledge the Lallemand (China) for supplying the yeast products.

\section{References}

[1] Anadón A, The EU ban of antibiotics as feed additives: alternatives and consumer safety. Journal of Veterinary Pharmacology and Therapeutics, 2006. 29, 41-44.

[2] Ondarza MB de, Sniffen CJ, Graham H and Wilcock P, Case study: Effect of Supplemental Live Yeast on Yield of Milk and Milk Components in High-Producing Multiparous Holstein Cows. The Professional Animal Scientist, 2010, 26, 443-449.

[3] Brossard L, Chaucheyras-Durand F, Michalet-Doreauand B and Martin C, Dose effect of live yeasts on rumen microbial communities and fermentations during butyric latent acidosis in sheep: new type of interaction.Animal Science, 2006. 82, 829-836.

[4] Moallem U, Lehrer H, Livshitz L, Zachut M and Yakoby S, The effects of live yeast supplementation to dairy cows during the hot season on production, feed efficiency, and digestibility. Journal of Dairy Science, 200992, 343-351.

[5] Chaucheyras-Durand F, Walker ND, Bach A, Effects of active dry yeasts on the rumen microbial ecosystem: Past, present and future. Animal Feed Science and Technology, 2008145, 5-26.

[6] Bach A, Iglesias C, Devant M, Daily rumen $\mathrm{pH}$ pattern of loosehoused dairy cattle as affected by feeding pattern and live yeast supplementation. Animal Feed Science and Technology, 2007,136, 146-153.

[7] Carro MD, Lebzien P, and Rohr K. Influence of yeast culture on the in vitro fermentation (Rusitec) of diets containing variable portions of concentrates. Animal Feed Science and Technology, 1992, 37, 209-220.

[8] Mutsvangwa T, Edwards IE, Topps JH and Paterson GFM, The effect of dietary inclusion of yeast culture (Yea-Sacc) on patterns of rumen fermentation, food intake and growth of intensively fed bulls. Animal Production, 1992. 55, 35-40.

[9] Mir Z and Mir PS, Effect of the Addition of Live Yeast (Saccharomyces cerevisiae) on Growth and Carcass Quality of Steers Fed High-Forage or High Grain Diets and on Feed Digestibility and In Situ Degradability. Journal of Animal Science, 199472, 537-545.

[10] Guedes CM, Gongalves D, Rodrigues MAM, Dias-da-Silva A. Effects of a Saccharomyces cerevisiae yeast on ruminal fermentation and fibre degradation of maize silages in cows. Animal Feed Science and Technology, 2008,145, 27-40.

[11] Desnoyers M, Giger-Reverdin S, Bertin G, Duvaux-Ponter C and Sauvant D. Meta-analysis of the influence of Saccharomyces cerevisiae supplementation on ruminal parameters and milk production of ruminants. Journal of Dairy Science. 2009,92, 16201632.

[12] NRC, Nutrient Requirement of Beef Cattle: Seventh Revision Editon: Update 2000. National Academy of Science, Washington DC. 
[13] Ørskov ER, DeB Hovell FD \& Mould F, The use of the nylon bag technique for the evaluation of feedstuffs. Tropical Animal Production, 1980, 5, 195-213.

[14] YU P Q and Niu ZY. Using a complex non-TDN based model (the $D V E / O E B$ system) to predict microbial protein synthesis, endogenous protein, degradation balance, and total truly absorbed protein supply of different varieties of cereal oats for ruminants. Animal Science Journal, 2009, 80, 273-279.

[15] Jensen C, Weisbjerg M R, Nørgaard P, Hvelplund T, Effect of maize silage maturity on site of starch and NDF digestion in lactating dairy cows. Animal Feed Science and Technology, 2005, 118, 279-294.

[16] Van Soest PJ, Robertson J.B., Lewis BA, Methods for dietary fiber neutral detergent fiber, and non starch polysaccharides in relation to animal nutrition. Journal of Dairy Science, 1991,74, 3583-3597.

[17] Hristov AN, Varga G, Cassidy T, Long M, Heyler K, Karnati SKR, Corl B, Hovde CJ and Yoon I,. Effect of Saccharomyces cerevisiae fermentation product on ruminal fermentation and nutrient utilization in dairy cows. Journal of Dairy Science, 2010, 93, 682692.

[18] Chaney A and Marbach EP. Modified reagents for determination of urea and ammonia. Clinical Chemistry, 1962, 8, 130-132.

[19] Mu HJ, Meng QX, Ren LP, Wang L, Simultaneous determination of lactic acid and volatile fatty acids in ox rumen juice by ion chromatography. PTCA (PART B: CHEM. ANAL), 2009, 45, 5255.

[20] Yue Q, Yang HJ, Li DH, Wang JQ, A comparison of HPLC and spectrophotometrical methods to determine the activity of ferulic acid esterase in commercial enzyme products and rumen contents of steers. Animal Feed Science and Technology, 2009,153, 169177.

[21] Dashtban M, Maki M, Leung KT, Mao CQ and Qin WS, Cellulase activities in biomass conversion: measurement methods and comparison. Critical Reviews in Biotechnology, 2010, 30, 302309.

[22] Na RH, Dong HM, Zhu ZP, Chen YX, Effects of forage type and dietary concentrate to forage ratio on methane emission and rumen fermentation characteristics of dairy cows in China. Agricultural and Biosystems Engineering, 2013, 56, 1115-1122.

[23] Church DC, The Ruminant Animal: Digestive Physiology and Nutrition, pp.147. Prentice Hall, Englewood Cliffs. 1988.

[24] Bach A, Calsamiglia S, Stern MD, Nitrogen metabolism in the rumen. Journal of Dairy Science, 2005, 88, 9-21.

[25] Chaucheyras F, Fonty G, Bertin G, Salmon JM, Gouet P, Effects of a strain of Saccharomyces cerevisiae (Levucell SC), a microbial additive for ruminants, on lactate metabolism in vitro. Canadian Journal of Microbiology, 1996, 42, 927-933.

[26] Newbold CJ, McIntosh FM, Wallace RJ, Changes in the microbial population of a rumen-simulating fermenter in response to yeast culture. Canadian Journal of Animal Science, 1998, 78, 241-244.

[27] Rossi F, Luccia A D, Vincenti D, Cocconcelli PS, Effects of peptidic fractions from Saccharomyces cerevisiae culture on growth and metabolism of the ruminal bacteria Megasphaera elsdenii. Animal Research, 2004, 53, 177-186.

[28] Monnerat JP, Paulino PV, Detmann E, Valadares FSC, Valadares $\mathrm{RD}$, Duarte MS, Effects of Saccharomyces cerevisiae and monensin on digestion, ruminal parameters, and balance of nitrogenous compounds of beef cattle fed diets with different starch concentrations. Tropical Animal Health and Production, 2013,45, 1251-1257.

[29] Williams PE, Tait CA, Innes GM, Newbold CJ, Effects of the inclusion of yeast culture (Saccharomyces cerevisiae plus growth medium) in the diet of dairy cows on milk yield and forage degradation and fermentation patterns in the rumen of steers. Journal of Animal Science,1991,69, 3016-3026

[30] Ding J, Zhou ZM, Ren LP and Meng QX, Effect of Monensin and Live Yeast Supplementation on Growth Performance, Nutrient Digestibility, Carcass Characteristics and Ruminal Fermentation Parameters in Lambs Fed Steam-flaked Corn-based Diets. AsianAustralasian Journal of Animal Science, 2008 21, 547-554

[31] Arcos-Garcia JL, Castrejon FA, Mendoza GD, Pérez-Gavilán EP, Effect of two commercial yeast cultures with Saccharomyces cerevisiae on ruminal fermentation and digestion in sheep fed sugar cane tops. Livestock Production Science, 2000, 63, 153-157.

[32] Putnam D E, Schwab CG, Socha MT, Whitehouse NL, Kierstead NA, Garthwaite BD. Effect of yeast culture in the diets of early lactation dairy cows on ruminal fermentation and passage of nitrogen fractions and amino acids to the small intestine. Journal of Dairy Science, 1997, 80, 374-384.

[33] Thrune M, Bach A, Ruiz-Moreno M, Stern MD, Linn JG, Effects of Saccharomyces cerevisiae on ruminal $\mathrm{pH}$ and microbial fermentation in dairy cows: Yeast supplementation on rumen fermentation. Livestock Science, 2009, 124, 261-265.

[34] Chaucheyras-Durand F, Fonty G, Establishment of cellulolytic bacteria and development of fermentative activities in the rumen of gnotobiotically-reared lambs receiving the microbial additive Saccharomyces cerevisiae CNCM I-1077. Reproduction Nutrition Development, 2001, 41, 57-68.

[35] Russell JB, Wilson DB, Why are ruminal cellulolytic bacteria unable to digest cellulose at low $\mathrm{pH}$ ? Journal of Dairy Science, 1996, 79, 1503-1509.

[36] Chaucheyras-Durand F and Fonty G, Influence of a probiotic yeast (Saccharomyces cerevisiae CNCM I-1077) on microbial colonization and fermentation in the rumen of newborn lambs. Microbial Ecology in Health and Disease, 2002, 14, 30-36.

[37] Jouany JP, Mathieu F, Senaud J, Bohatier J, Bertin G, Mercier M, The effect of Saccharomyces cerevisiae and Aspergillus oryzae on the digestion of the cell wall fraction of a mixed diet in defaunated and refaunated sheep rumen. Reproduction Nutrition Development, 1998, 38, 401-416.

[38] Marden JP, Julien C, Monteils V, Auclair E, Moncoulon R and Bayourthe C. How does live yeast differ from sodium bicarbonate to stabilize ruminal $\mathrm{pH}$ in high-yielding dairy cows? Journal of Dairy Science, 2008, 91, 3528-3535.

[39] Corona L, Mendoza GD, Castrejon FA, Crosby MM, Cobos MA Evaluation of two yeast cultures (Saccharomyces cerevisiae) on ruminal fermentation and digestion of feed fed a corn stover diet. Small Ruminant Research, 1999, 31, 209-214.

[40] Enjalbert F, Garrett JE, Moncoulon R, Bayourthe C, Chicoteau P Effects of yeast culture (Saccharomyces cerevisiae) on ruminal digestion in non-lactating dairy cows. Animal Feed Science and Technology, 1999. 76, 195-206.

[41] Kowalik B, Michałowski T, Pająk JJ, Aciak MT and Zalewska M. The effect of live yeast, Saccharomyces cerevisiae, and their metabolites on ciliate fauna, fibrolytic and amylolytic activity, carbohydrate digestion and fermentation in the rumen of goats. Journal of Animal and Feed Science, 2011, 20, 526-536. 